\title{
O Programa Português para Estrangeiros: panorama de ações e contribuições para a educação de professores de PLA
}

\section{The "Portuguese for Foreigners" Program: an overview of actions and contributions to the education of PAL teachers}

\section{El Programa Português para Estrangeiros: panorama de las acciones y contribuciones a la educación de profesores de PLA}

\author{
Vanessa Doumid Damasceno ${ }^{1}$ \\ Helena Vitalina Selbach²
}

https://orcid.org/0000-0002-3637-2397

https://orcid.org/0000-0001-9957-8328

\begin{abstract}
RESUMO: Inscrito no escopo da Linguística Aplicada, este artigo objetiva traçar um histórico das ações promovidas pelo Programa Português para Estrangeiros (PPE) desenvolvido na Universidade Federal de Pelotas a fim de contribuir com o debate sobre a construção da área de ensino e aprendizagem de Português Língua Estrangeira (PLE) a partir de contextos e práticas situadas. Apresentamos um panorama das ações realizadas, das temáticas abordadas e dos pressupostos que embasam as práticas no PPE, como os Novos Estudos de Letramento, a fim de discutir as contribuições do Programa para a formação/educação de professores na área de Português como Língua Adicional (PLA). Para tanto, realizamos um levantamento das edições e dos cursos ofertados pelo PPE. Os resultados indicam que o Programa subsidia a formação/educação de professores para a atuação na área de PLA, ainda tão escassa em Cursos de Letras no Brasil, na medida em que os discentes têm a oportunidade de participar em variadas ações formativas. Com a oferta e construção dos cursos, o PPE busca não somente qualificar os discentes que têm a possibilidade de futura atuação na área, mas também incentivar a reflexão sobre a atividade docente em PLA e sobre as especificidades que dela fazem parte.
\end{abstract}

PALAVRAS-CHAVE: Português como Língua Adicional. Ensino. Educação de professores.

\footnotetext{
ABSTRACT: Inscribed in the scope of Applied Linguistics, this article aims to trace a history of the actions promoted by the "Portuguese for Foreigners" Program (PFP) developed at the Federal University of Pelotas in order to contribute to the debate on the construction of the teaching and learning area of Portuguese as a Foreign Language (PFL) from contexts and situated practices.

1 Vanessa Doumid Damasceno é doutora em Letras e professora adjunta do Centro de Letras e Comunicação da Universidade Federal de Pelotas. E-mail: vanessaddclc@gmail.com.

${ }^{2}$ Helena Vitalina Selbach é doutora em Estudos Linguísticos e professora adjunta do Centro de Letras e Comunicação da Universidade Federal de Pelotas. E-mail: helena.selbach@ufpel.edu.br.
} 
We present an overview of the actions taken, the themes addressed and the assumptions that underlie the practices in the PFP, such as the New Literacy Studies, in order to discuss the Program's contributions to the training/education of teachers in the area of Portuguese as an Additional Language (PAL). Therefore, we carried out a survey of the editions and courses offered by the PFP. The results indicate that the Program subsidizes the training/education of teachers to work in the area of PAL, which is still so scarce in Letters Courses in Brazil, as students have the opportunity to participate in various training/educational actions. With the offer and construction of the courses, PFP seeks not only to qualify students who have the possibility of future work in the area, but also to encourage reflection on the teaching activity in PAL and on the specificities that are part of it.

KEYWORDS: Portuguese as Additional Language. Teaching. Teacher education.

RESUMEN: Inscrito en el campo de la Lingüística Aplicada, este artículo tiene el objetivo de trazar un histórico de las acciones impulsadas por el Programa Português para Estrangeiros (PPE) desarrollado en la Universidade Federal de Pelotas con la intención de contribuir con el debate sobre la construcción del área de enseñanza y aprendizaje de Português Língua Estrangeira (PLE) a partir de contextos y prácticas situadas. Presentamos un panorama de las acciones desarrolladas, las temáticas abordadas y los presupuestos teóricos que sostienen las prácticas en el PPE, como los Novos Estudos de Letramento, a fin de discutir las contribuciones del Programa para la formación/educación de profesores en el área de Português como Língua Adicional (PLA). Por ello, realizamos un relevamiento de las ediciones y cursos que ofrece el PPE. Los resultados indican que el Programa subsidia la formación/educación de profesores para actuar en el área de PLA, que aún es tan escasa en los Cursos de Letras en Brasil, a medida que los estudiantes tienen la oportunidad de participar en diversas acciones formativas. Con la oferta y construcción de los cursos, el PPE busca no solo capacitar a los estudiantes que tienen la posibilidad futura de trabajar en el área, sino también incentivar la reflexión sobre la actividad docente en PLA y sobre las especificidades que forman parte de ella.

PALABRAS CLAVE: Portugués como lengua adicional. Enseñanza. Formación de profesores.

\section{Introdução}

A Universidade Federal de Pelotas (UFPel) é uma das Instituições de Ensino Superior (IES) brasileiras voltadas à internacionalização; apresenta uma série de ações em internacionalização articuladas com diversos convênios interinstitucionais firmados e ativos, com extensa mobilidade acadêmica (UFPel, 2018). Em 2016, ocorreu a criação da Coordenação Pedagógica da área de Português para Estrangeiros no programa Idiomas sem Fronteiras. Em 2017, foi criado o Programa Português para Estrangeiros (PPE), com o objetivo de fomentar ações de internacionalização da universidade que, em 2018, aprovou seu Plano de Planejamento Estratégico de Internacionalização, o qual prevê a expansão e a promoção do estudo de Português para Estrangeiros na universidade por meio de uma série de estratégias que envolvem: 1) a oferta contínua do ensino de Língua Portuguesa (LP) a estrangeiros, 2) a divulgação da aplicação do 
exame Celpe-Bras para a comunidade acadêmica da UFPel e para as universidades parceiras estrangeiras e 3) a definição da área de Português para Estrangeiros como prioridade institucional e área estratégica da universidade a fim de atrair alunos estrangeiros e difundir a cultura brasileira (UFPel, 2018).

Em 2020, um novo marco na história da universidade envolve e impacta diretamente a área de Português como Língua Adicional (PLA): a instituição da Política Linguística da UFPel, cujos objetivos são: "viabilizar o acolhimento, a formação e o acompanhamento em língua portuguesa para falantes de outras línguas" e "promover ensino, pesquisa e extensão em português como língua adicional"; as ações, por sua vez, envolvem a "oferta de cursos de português para falantes de outras línguas" e o "incentivo à institucionalização do Português como Língua adicional no Centro de Letras e Comunicação" (UFPel, 2020, p. 2-3).

O PPE da UFPel, aprovado em 2018 como um Programa Estratégico Institucional, nasceu como projeto de ensino que buscava atender à crescente demanda de alunos estrangeiros em cursos de graduação e pós-graduação e à chegada de imigrantes e refugiados ao município de Pelotas/RS. Buscava proporcionar ferramentas linguísticas, discursivas e culturais aos estrangeiros da universidade, assim como aos estrangeiros da comunidade externa. O Programa também buscava servir como um espaço de formação/educação profissional e continuada para os graduandos dos Cursos de Letras do Centro de Letras e Comunicação (CLC) da UFPel.

Neste artigo, inscrito no escopo da Linguística Aplicada, a partir dessa contextualização inicial, nosso objetivo é traçar um histórico das ações promovidas pelo PPE da UFPel a fim de contribuir com o debate sobre a construção da área de ensino e aprendizagem de Português Língua Estrangeira (PLE) a partir de contextos e práticas situadas. Apresentamos um panorama das ações realizadas, das temáticas abordadas e dos pressupostos que embasam as práticas no PPE, a fim de discutir as contribuições do Programa para a formação/educação de professores na área de PLA. Para tanto, levantamos as edições e os cursos ofertados pelo PPE. Na próxima seção, apresentamos o Programa e seus conceitos norteadores para, em seguida, apresentar e discutir os cursos e as ações do programa como subsídios à formação/educação de professores de PLA e à implementação dos objetivos da internacionalização da UFPel. 


\section{O PPE e seus conceitos norteadores}

O PPE é um jovem programa ligado à Pró-reitoria de Ensino da UFPel que desenvolve práticas de ensino voltadas aos estudantes estrangeiros da Instituição e do município de Pelotas desde 2017. Até o ano de 2017, a UFPel ofertava cursos esporádicos de extensão de curta duração como forma de atender a demandas específicas. Em maio de 2017, o Projeto Estratégico Português para Estrangeiros é criado e, dois anos depois, em maio de 2019, a UFPel aplica o exame Certificado de Proficiência em Língua Portuguesa para Estrangeiros (Celpe-Bras), pela primeira vez.

O principal objetivo do PPE é promover e qualificar uma educação linguística em LP que abranja as variadas relações interculturais e que possibilite que os estudantes estrangeiros exerçam sua cidadania por meio da participação em práticas sociais em LP nas mais diferentes esferas de atuação dentro e fora da IES. Entendemos que os princípios educativos relevantes para o contexto de ensino de PLA aproximam-se dos propostos nos Referenciais Curriculares do Estado do Rio Grande do Sul, em especial, dos conceitos de fruição e cidadania.

[...] Por fruição entende-se o prazer, o entretenimento, a apreciação estética do mundo, o desenvolvimento da curiosidade intelectual e do gosto pelo conhecimento; entende-se também a atitude de quem se vale de oportunidades, e se permite vivenciar as múltiplas faces da vida humana. Basta dar uma olhada nos dicionários da língua: fruir é, ao mesmo tempo, fazer uso de uma oportunidade e ter prazer: não se pode esquecer que uma expressão consagrada em nossa língua é "gozar de um direito". [...] Já a cidadania [...] deve ser entendida aqui em sua acepção mais básica de convivência: co-presença e interação entre homens livres na "cidade". A consciência do outro, ao mesmo tempo limite, espelho e aliado, remete, de um lado, à necessidade da busca de negociação de conflitos e, de outro, ao potencial de, em colaboração, superar o que seria possível a cada um realizar isoladamente. (RIO GRANDE DO SUL, 2009, p. 39).

Schlatter, Bulla e Costa (2020, p. 495), indicam que algumas especificidades de PLA no contexto latino-americano dizem respeito

[...] às relações que podem ser estabelecidas entre proximidades linguísticas e sócio-históricas. Isso inclui, por exemplo, refletir acerca dos usos das línguas nesse cenário em diferentes esferas de atuação, da necessidade de distinguir português e espanhol e para quais finalidades, das (im)possibilidades de intercompreensão, das demandas por determinados níveis de proficiência como marcadores de diferenças sociais, como porta de acesso ou barreira à cidadania, a bens culturais e à circulação em diferentes espaços sociais (SCHLATTER; BULLA; COSTA, 2020, p. 495). 
Concordamos com a necessidade de avaliar constantemente essas especificidades que também impactam a formação/educação de professores de PLA, uma vez que aprendizagem, no contexto acadêmico, implica adaptação dos estudantes a "novas formas de entender, interpretar e organizar o conhecimento" (LEA; STREET, 1998, p. 158). Aprendizagem e ensino, a partir perspectiva dos Novos Estudos de Letramento, são situados e socioculturais, sensíveis aos contextos nos quais ocorrem; valorizam e celebram a diversidade social, linguística e cultural dos estudantes na educação superior, desafiando e superando o discurso de déficit atribuído aos discentes (LILLIS; SCOTT, 2007).

Ainda com relação ao embasamento teórico na área de ensino e aprendizagem que subsidia o Programa, afiliamo-nos à perspectiva sociocultural, para a qual a aprendizagem de uma língua se dá por meio de participação em práticas sociais situadas; ocorre "através de processo colaborativo por meio do qual os aprendizes se apropriam da língua de sua própria interação, para seus próprios propósitos, construindo a competência gramatical, expressiva e cultural" (OHTA, 2000, p. 51 apudPAIVA, 2014, p. 138). Paiva (2014) aponta ainda a aquisição da língua adicional como um processo no qual os estudantes tornam-se membros e participam de uma comunidade de usuários desse idioma. Nessa perspectiva, a aprendizagem caracteriza-se como um processo gradativo de acesso a práticas sociais de participação de aprendizes em comunidades de prática, chamada de Participação Periférica Legítima: "o processo pelo qual recémchegados tornam-se parte de uma comunidade de prática" (LAVE; WENGER, 1991, p. 29). Esse acesso e interação, propulsores de aprendizagem, produção e acúmulo de conhecimento a partir de interesses compartilhados entre participantes, promove também um vínculo, criado pelo valor conferido à aprendizagem conjunta; esse valor possibilita que, ao longo do tempo, essa comunidade desenvolva práticas, abordagens e um corpo de conhecimento comum, bem como relações pessoais e formas estabelecidas de interação (WENGER; MCDERMOTT; SNYDER, 2002). O conhecimento de uma comunidade reside, assim, nas habilidades e relações entre seus participantes, bem como nos documentos e instrumentos que materializam aspectos desse conhecimento (WENGER; MCDERMOTT; SNYDER, 2002).

Transpomos, ainda, para o nosso contexto acadêmico, o pressuposto indicado nos Referenciais Curriculares do Estado do Rio Grande do Sul (RIO GRANDE DO SUL, 2009, 
p. 39) de que "[a] escola é lugar privilegiado para a aprendizagem da solidariedade, para a formação do senso ético e para a participação". O PPE e suas ações de ensino de PLA, que integram as políticas de internacionalização e de promoção da área de PLA na UFPel, buscam ser um lócus 1) de acesso e participação em comunidades de prática de LP, 2) de promoção de ensino e práticas situadas que valorizam a fruição, o exercício da cidadania, da solidariedade e do senso ético e 3) de subsídio à formação/educação crítica em PLA dos alunos do CLC, futuros professores, no que diz respeito ao planejamento de aulas e cursos, incluindo o curso preparatório para o Celpe-Bras, a discussões teóricas, à elaboração de material didático e a um ensino teoricamente informado, como apresentamos na próxima seção.

\section{Os cursos e as ações do PPE}

Desde a sua criação, o PPE já atendeu a mais de 300 estudantes e ofertou mais de 30 cursos gratuitamente. Dentre os participantes estrangeiros recebidos no Projeto, muitos vêm para cursar pós-graduação - mestrado e doutorado - ou realizar estágio de pesquisa. Outros estudantes buscam cursar uma graduação por meio de convênios ou de mobilidade acadêmica. $O$ interesse comum entre estudantes de graduação e de pós é 0 de produzir pesquisas, relatórios, redigir artigos acadêmicos ou realizar o Exame CelpeBras.

Os cursos do PPE tiveram início oficialmente em 2017/1, com o objetivo de ensinar LP e Cultura Brasileira para os Estrangeiros de Mobilidade Internacional acadêmica na UFPel, proporcionando-Ihes educação linguística em LP e suporte socioeducacional no que diz respeito à imersão e inserção social na cidade de Pelotas e no Brasil. $O$ intuito era também prepará-los para o exame Celpe-Bras, uma vez que esse exame é requerido por alguns programas de pós-graduação da universidade para certificar a proficiência em LP desses discentes, ao término dos estudos no Brasil.

As turmas dos cursos do PPE são formadas após uma avaliação diagnóstica de conhecimento de LP e de levantamento de interesses. A duração dos cursos se ajusta ao calendário acadêmico da UFPel e os estudantes recebem avaliação sistemática e contínua dos seus desempenhos. Os cursos são ministrados por estudantes do CLC (bolsistas e voluntários), sob a orientação da professora coordenadora do projeto. As temáticas dos cursos já ofertados aos alunos estrangeiros são: 1) Aspectos da cultura brasileira, 2) Português básico, 3) Leitura e produção de textos acadêmicos, 4) Oralidade e 
O Programa Português para Estrangeiros: panorama de ações e contribuições para a educação de professores de PLA

compreensão oral e 5) Preparatório para o exame Celpe-Bras. Os dois cursos mais ofertados são Aspectos da cultura brasileira e Preparatório para o exame Celpe-Bras. A Tabela 1 compila os dados referentes à oferta de cursos do Programa que versam sobre essas temáticas.

Tabela 1 - Oferta de cursos do PPE

\begin{tabular}{c|l|}
\hline $\begin{array}{c}\text { ANO/SEMESTR } \\
\text { E }\end{array}$ & \multicolumn{1}{c}{ Curso } \\
\hline $2017 / 1$ & Preparatório para o Exame Celpe-Bras \\
\hline $2017 / 1$ & Leitura e produção escrita em Língua Portuguesa \\
\hline $2018 / 1$ & Oralidade e compreensão oral \\
\hline $2018 / 2$ & Português Básico I \\
\hline $2018 / 2$ & Familiarização com o Exame Celpe-Bras \\
\hline $2018 / 2$ & Português Língua Estrangeira: Leitura e produção de textos acadêmicos \\
\hline $2019 / 1$ & Familiarização com o Exame Celpe-Bras \\
\hline $2019 / 1$ & Familiarização com a Língua Portuguesa \\
\hline $2019 / 2$ & Aspectos da Cultura Brasileira \\
\hline $2019 / 2$ & Familiarização com o Exame Celpe-Bras \\
\hline $2020 / 2$ & Aspectos da Cultura Brasileira \\
\hline $2020 / 2$ & Familiarização com o Exame Celpe-Bras \\
\hline $2021 / 1$ & Aspectos da Cultura Brasileira \\
\hline $2021 / 1$ & Familiarização com o Exame Celpe-Bras \\
\hline $2021 / 2$ & Aspectos da Cultura Brasileira \\
\hline $2021 / 2$ & Familiarização com o Exame Celpe-Bras \\
\hline
\end{tabular}

Fonte: Elaborado pelas autoras.

O curso de Aspectos da cultura brasileira busca aprofundar a interação pessoal e profissional dos estudantes estrangeiros com as culturas do Brasil. Enfoca aspectos da cultura brasileira que dizem respeito a interações cotidianas de estrangeiros que decidem viver no Brasil para estudar e/ou trabalhar. Os objetivos do curso contemplam 1) identificar aspectos da cultura brasileira no que diz respeito a interações, 2) agir a partir de escolhas em algumas situações culturais no Brasil e 3) reconhecer diferenças entre aspectos da cultura brasileira - em diferentes regiões do país - e de outras culturas que o estudante estrangeiro conhece. 
Os cursos Português básico e Familiarização com a Língua Portuguesa, por sua vez, enfocam o desenvolvimento das habilidades oral e escrita em LP e voltam-se tanto para situações de uso formal quanto coloquial da língua. Já Português Língua Estrangeira: Leitura e produção de Textos Acadêmicos exige, como pré-requisito, que o aluno tenha cursado um semestre na UFPel. O curso focaliza a leitura e a produção de textos acadêmicos em LP com ênfase no ensino de estratégias de leitura que possam otimizar a compreensão leitora e ampliar o conhecimento textual (lexical, gramatical e textualdiscursivo) e contextual (conhecimento de cultural e situacional). Objetiva desenvolver estratégias de leitura e produção e competências linguísticas necessárias para a compreensão de textos em contextos acadêmicos.

Oralidade e compreensão oral desenvolvem habilidades de produção e recepção oral a partir de gêneros discursivos orais da esfera acadêmica e do cotidiano. Já o curso Preparatório para o exame Celpe-Bras apresenta e explora o exame a partir da análise e prática dos gêneros discursivos característicos dos exames Celpe-Bras, possibilitando, aos alunos, construir estratégias para a realização das tarefas de produção oral e escrita.

Concomitantemente à oferta de cursos, no âmbito do ensino, o PPE também realiza ações extensionistas em LP, abertas à comunidade. Essas intervenções também contam com a participação dos alunos bolsistas e voluntários, professores em formação, na escolha das temáticas, na construção das propostas e na dinamização dessas práticas junto aos alunos estrangeiros. Constituem, juntamente com a oferta de cursos, ações que subsidiam a formação/educação de professores em PLA voltada a

[...] debates coletivos para compreender as potencialidades $\mathrm{e}$ responsabilidades da educação linguística e da atuação como professor em contextos específicos e também na interlocução com os pares. É função de uma proposta curricular promover desafios e debates que suscitem reflexões sobre valores políticos e ideológicos, sentidos historicamente associados a diferentes discursos e possibilidades de intervir de modo ético, autoral e criativo (SCHLATTER; BULLA; COSTA, 2020, p. 500).

As temáticas das intervenções são variadas e buscam viabilizar os objetivos previstos na Política Linguística e nas estratégias da internacionalização da UFPel, abrangendo aspectos da riqueza e da diversidade cultural do Brasil e da região Sul. A Tabela 2 disponibiliza os dados referentes a essas propostas. 
O Programa Português para Estrangeiros: panorama de ações e contribuições para a educação de professores de PLA

Tabela 2 - Ações do PPE

\begin{tabular}{|c|c|}
\hline $\begin{array}{l}\text { ANO/SEMESTR } \\
\text { E }\end{array}$ & Ação \\
\hline $2018 / 2$ & Noite do jogo: imagem e ação \\
\hline $2018 / 2$ & Percurso cultural \\
\hline $2018 / 2$ & Futebol, pertencimento e sociabilidade com o professor Luiz C. Rigo \\
\hline $2018 / 2$ & Noite do jogo: stop \\
\hline $2019 / 1$ & Posto aplicador do Celpe-Bras \\
\hline $2019 / 2$ & Recepção aos estrangeiros \\
\hline $2019 / 2$ & Português no mercado: aula na rua \\
\hline $2019 / 2$ & Sábado cultural: comida, futebol, música e dança \\
\hline $2019 / 2$ & Noite de Arte Brasileira com Drummond e Prof. Daniel Soares \\
\hline $2020 / 2$ & $\begin{array}{l}\text { Do bah ao vixe: ensino da cultura na aula do Português como Língua Adicional } \\
\text { com a professora Camila Oppelt }\end{array}$ \\
\hline $2020 / 2$ & $\begin{array}{l}\text { Português como língua de acolhimento: interculturalidade na construção de } \\
\text { práticas de letramento com Giuliano Pereira de Oliveira Castro }\end{array}$ \\
\hline $2020 / 2$ & $\begin{array}{l}\text { II Webinario del curso de Letras Español y Literatura Hispánica } \\
\text { Charlas desde la fronteira: Português para falantes de outras línguas }\end{array}$ \\
\hline $2021 / 1$ & $\begin{array}{l}\text { Diálogos sobre a Umbanda no Brasil: Um resgate histórico e cultural com Bruno } \\
\text { Oliveira }\end{array}$ \\
\hline $2021 / 1$ & $\begin{array}{l}\text { Reflexões sobre o processo de ensino da escrita no ensino de Português para } \\
\text { Estrangeiros com Nonato Furtado }\end{array}$ \\
\hline $2021 / 2$ & O que dançamos? Danças de nossas culturas! com Marcelo Silva \\
\hline $2021 / 2$ & $\begin{array}{l}\text { As várias faces da cultura tradicionalista gaúcha com a participação de Jenifer } \\
\text { Dias }\end{array}$ \\
\hline
\end{tabular}

Fonte: Elaborado pelas autoras

As atividades envolvem jogos, prática sociais brasileiras, como imagem e ação e stop, bem como temáticas variadas, que são debatidas e problematizadas por meio de aulas abertas.

Essas temáticas incluem discussões sobre alimentação, futebol, música, dança, arte, literatura, religiosidade, como em "Diálogos sobre a Umbanda" e cultura tradicionalista gaúcha. Há ainda eventos de recepção, de acolhimento aos estrangeiros que chegam à universidade e de aulas que acontecem fora da universidade, como é o caso de "Português no mercado: aula na rua" e "Percurso cultural", em que os estudantes percorrem a cidade e conhecem sua história, visitando monumentos e prédios históricos da cidade. 


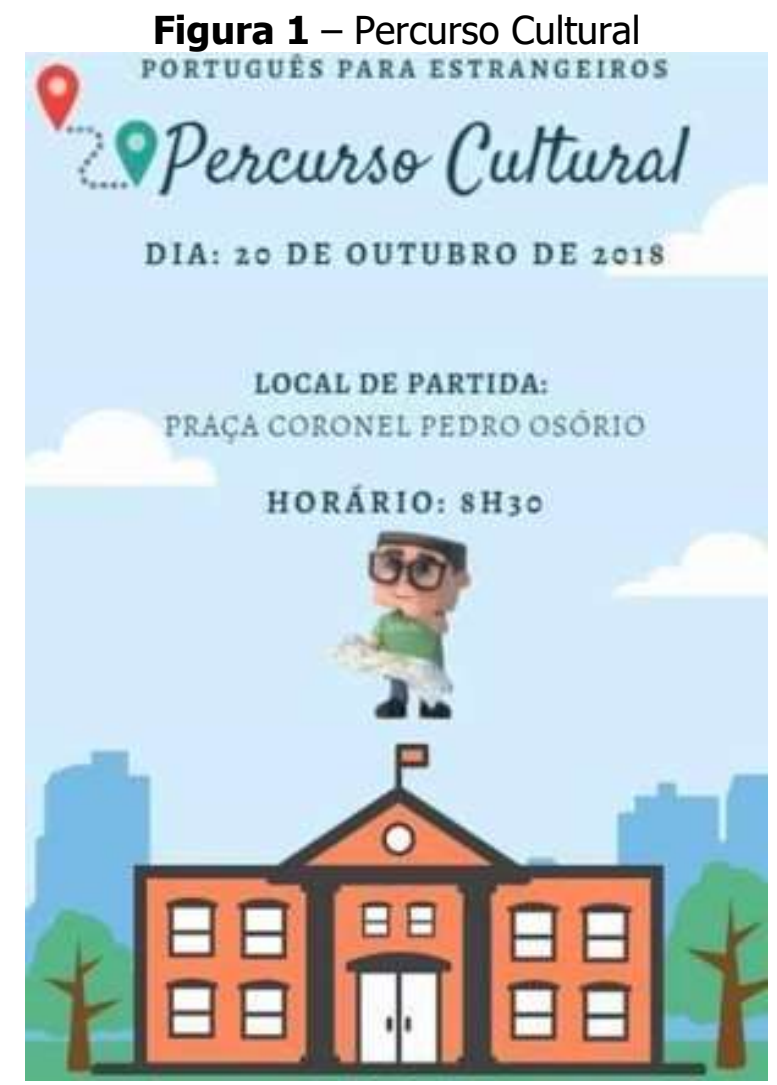

Fonte: PPE (2018)

O PPE é um programa que oferta cursos e realiza ações de ensino e de extensão. Para que o Programa se efetive, são previstas uma série de etapas que compreendem desde a seleção dos estudantes de Letras que irão atuar no Programa, à elaboração de material didático para os cursos e ao planejamento das atividades (aulas abertas e aplicação do Celpe-Bras). Essas práticas envolvem:

1. seleção dos ministrantes dos cursos (estudantes do Curso de Letras);

2. formação para a atuação nos cursos por meio de reuniões semanais de estudo que envolvem a realização de leituras e discussões de textos teóricos e metodológicos, integrando, assim, atividades de ensino e pesquisa;

3. diagnóstico do perfil dos estudantes estrangeiros por meio de realização de prova escrita e entrevista oral;

4. formação de grupos de alunos de PLA de acordo com o conhecimento de LP e língua de origem e

5. elaboração de plano de curso de PLA para os estudantes estrangeiros e de material didático para cada grupo, bem como planejamento de ações.

Essas etapas dizem respeito à dinâmica do PPE, que viabiliza diversas ações formativas. Essas práticas envolvem um trabalho colaborativo e uma construção conjunta entre a coordenação do projeto e os alunos de Letras na concepção e dinamização dos 
cursos, das aulas abertas e dos eventos em PLA.

\section{Considerações finais}

O PPE atende uma média de 40 alunos estrangeiros por semestre, advindos de diversos países e com variadas línguas maternas. A crescente procura pelos cursos de PLA oferecidos pela UFPel nos últimos anos impulsionou não só os estudos desenvolvidos na área, como também a oferta de cursos de formação continuada para estudantes da graduação.

Os cursos e as ações do PPE buscam auxiliar os estudantes estrangeiros em seu processo de aprendizagem da $L P$, o que pode refletir em habilidades comunicativas tanto na esfera acadêmica quanto cotidiana. Por meio dos cursos e das ações realizadas pelo Programa, os estudantes estrangeiros - e os alunos de Letras - têm a oportunidade de refletir sobre a LP e seus diversos usos, assim como sobre a diversidade cultural brasileira a partir da perspectiva intercultural que informa os cursos. Aos estudantes de Letras, o Programa possibilita a formação na área de PLA, ainda tão escassa em Cursos de Letras no Brasil. A UFPel, por sua vez, conta com o programa desde 2017, um projeto de inserção dos estudantes estrangeiros em práticas sociais em LP que viabiliza estratégias de internacionalização e da política linguística da instituição, como oferta contínua de LP a estrangeiros, aplicação do exame Celpe-Bras, acolhimento dos estudantes estrangeiros e afirmação da área de Português para Estrangeiros como prioritária e estratégica para o desenvolvimento da universidade.

O Programa subsidia a formação/educação de professores para a atuação na área de PLA na medida em que os discentes têm a oportunidade de participar em variadas ações formativas que abrangem desde a concepção, o planejamento, à dinamização de cursos e ações. Com a oferta e construção dos cursos, o PPE busca não somente qualificar os discentes que têm a possibilidade de futura atuação na área, mas também incentivar a reflexão sobre a atividade docente em PLA e sobre as especificidades que dela fazem parte.

\section{Referências}

LAVE, Jean; WENGER, Etienne. Situated learning: legitimate peripheral participation. New York: Cambridge University Press, 1991. 
LEA, Mary R.; STREET, Brian V. Student writing in higher education: an academic literacies approach. Studies in Higher Education, Dorchester on Thames, v. 23, n. 2, p. 157-172, 1998.

LILLIS, Teresa; SCOTT, Mary. Defining academic literacies research: issues of epistemology, ideo- logy and strategy. Journal of Applied Linguistics, [S. I.], v. 4, n. 1, p. 5-32, 2007.

PAIVA, Vera Lúcia Menezes de Oliveira e. Teoria Sociocultural. In: PAIVA, Vera Lúcia Menezes de Oliveira e. Aquisição de segunda língua. São Paulo: Parábola Editorial, 2014. p. 127-140.

RIO GRANDE DO SUL. Secretaria de Estado da Educação. Departamento Pedagógico. Referenciais curriculares do Estado do Rio Grande do Sul: lições do Rio Grande: Linguagens, Códigos e suas Tecnologias; Língua Portuguesa e Literatura; Língua Estrangeira Moderna. Porto Alegre: SE/DP, 2009, v. 1. Disponível em:

https://servicos.educacao.rs.gov.br/dados/refer curric vol1.pdf. Acesso em: 20 set. 2021.

SCHLATTER, Margarete; BULLA, Gabriela da Silva; COSTA, Everton Vargas da. Português como Língua Adicional: uma entrevista com Margarete Schlatter. ReVEL, [s. l.], v. 18, n. 35, p. 489-508, 2020.

UFPel - UNIVERSIDADE FEDERAL DE PELOTAS. Conselho Coordenador do Ensino, da Pesquisa e da Extensão. Resolução n. 06/2018, de 21 de abril de 2018. aprova o plano de planejamento estratégico de internacionalização da Universidade Federal de Pelotas. Pelotas: Conselho Coordenador do Ensino, da Pesquisa e da Extensão, 2018. Disponível em: https://wp.ufpel.edu.br/scs/files/2018/06/SEI Resolu\%C3\%A7\%C3\%A3o062018.pdf. Acesso em: 5 out. 2021.

UFPel - UNIVERSIDADE FEDERAL DE PELOTAS. Conselho Coordenador do Ensino, da Pesquisa e da Extensão. Resolução no 01/2020, de 20 de fevereiro de 2020. Institui a política linguística da Universidade Federal de Pelotas (UFPel). Pelotas: Conselho Coordenador do Ensino, da Pesquisa e da Extensão, 2020. Disponível em: https://ccs2.ufpel.edu.br/wp/wp-content/uploads/2020/03/Res.-01.2020-PoliticaLinguistica-Institucional-da-UFPel.pdf. Acesso em: 5 out. 2021.

WENGER, Etienne; MCDERMOTT, Richard A.; SNYDER, William Snyder . Cultivating communities of practice: a guide to managing knowledge. Boston: Harvard Business School Press, 2002.

Submetido em: 06 out. 2021. Aceito em: 26 out. 2021. 